\title{
OVERT TRANSLATION STRATEGIES IN THE HISTORIES OF ROBERT LOWELL AND EZRA POUND
}

\author{
Anthony Pym $^{1 *}$ \\ ${ }^{1}$ Universitat Rovira i Virgili, Tarragona, Espanha \\ Tradução de: \\ Juliana Steil ${ }^{2 * *}$ \\ ${ }^{2}$ Universidade Federal de Pelotas, Pelotas, Brasil \\ Otávio Guimarães Tavares ${ }^{3 *}$ \\ ${ }^{3}$ Universidade Federal do Pará, Belém, Brasil
}

\section{Abstract}

The present article analyzes the overt translation strategies in Robert Lowell's Imitations and Ezra Pound's The Cantos, indicating the conscious use of error as a compositional principle for the construction of knowledge through the distance of foreign documents.

Keywords: Overt translation strategies; Robert Lowell; Imitations; Ezra

Pound; The Cantos.

\section{ESTRATÉGIAS DE TRADUÇÃO MANIFESTA NAS HISTÓRIAS DE ROBERT LOWELL E EZRA POUND}

\section{Resumo}

Este artigo $^{1}$ apresenta uma análise de estratégias de tradução manifesta nas obras de Robert Lowell e de Ezra Pound, apontando, particularmente em Imitations e nos Cantos, a utilização consciente do erro, como princípio de composição, para construir conhecimento a partir da distância dos documentos estrangeiros.

Palavras-chave: Estratégias de tradução manifesta; Robert Lowell; Imitations; Ezra Pound; The Cantos.

\footnotetext{
" Professor da Universitat Rovira i Virgili e da University of Melbourne, desenvolve pesquisa sobre tradução e relações interculturais. Entre suas publicações estão Translation Solutions for Many Languages - Histories of a Flawed Dream (2016), On Translator Ethics - Principles for Mediation Between Cultures (2012), Exploring Translation Theories (2010; 2014), Method in Translation History (1998), Epistemological Problems in Translation and its Teaching (1993) e Translation and Text Transfer - An Essay on the Principles of Intercultural Communication (1992). ORCID: 0000-0002-9440-0886

${ }^{*}$ Lecturer in Translation Studies at the Universidade Federal de Pelotas (UFPel), Pelotas, Brazil. Her research interests revolve around literary translation and the work of William Blake. Among her translations to Brazilian Portuguese are Edith Wharton's The Age of Innocence, with Jonas Tenfen (Record, 2011; Folha de São Paulo, 2017), and Anthony Pym's Exploring Translation Theories, in collaboration with Rodrigo Borges de Faveri and Claudia Borges de Faveri (Perspectiva, 2017). julianasteil@gmail.com. ORCID: 0000-0002-7336-0299

${ }^{* * *}$ Lecturer in Anglophone Literatures at the Universidade Federal do Pará (UFPA), Belém, Brazil, where he coordinates the NELAA - Research Group in Anglophone Literatures and Arts. His current research revolves around the concepts of artifactuality and performativity of literature within the fields of literary theory, aesthetics and philosophy of art, and experimental forms of literature.nonada1@gmail.com, otaviogt@ufpa.br. ORCID: 0000-0002-1083-6448
} 
Os tradutores literários estadunidenses trabalham, em geral, numa indústria de pesquisa acadêmica dedicada à anexação do capital cultural estrangeiro. Entre os principais produtos dos melhores departamentos em literatura estão a edição anotada, o estudo biográfico especializado e a tradução bem explicada, todos quase sempre apresentados no mais claro inglês disponível. A história literária - uma coordenação narrativa de documentos - está, nesse sentido, fortemente ancorada na arqueologia bibliográfica - identificação e descrição dos próprios documentos -, consolidando, inevitavelmente, qualquer inovação nas notas de rodapé de um vasto banco de informações que envolve os legados de todas as civilizações passadas e concorrentes. Geralmente, a concentração cultural acompanha a extensão do controle econômico: os grandes museus e bibliotecas do mundo sempre se desenvolveram junto às sedes do poder imperial. O fato de haver cerca de 6.700 museus nos Estados Unidos, contudo, não significa automaticamente que todos eles abrigam troféus de conquista. Eles também refletem uma certa obsessão pela relativa falta de um passado autóctone e, consequentemente, por uma forma peculiar de historicização imediata. A arqueologia popular pode estabelecer relações não apenas com a história da fabricação estadunidense de bebida, com o rock and roll, com o descarte de lixo ou com qualquer forma ligeiramente distante de vida cotidiana - tudo isso a fim de, principalmente, promover o turismo doméstico -, mas também com o turismo internacional dos próprios estadunidenses, como um meio de idealizar e muitas vezes importar os objetos de um passado europeu. Num contexto consumista onde a moda do ano que passou é peça de museu no ano seguinte, é possível a ocorrência de um conflito entre a historicidade autóctone consciente ou inconscientemente projetada para distanciar um objeto em relação ao presente - e a historicidade dos objetos importados de culturas mais antigas - caso em que a distância extrema é antes considerada um potencial obstáculo para a compreensão e, portanto, um fator a ser reduzido. Idealmente, estes dois processos supririam a descontinuidade resultante da descoberta de um Novo Mundo. Na prática, o conflito entre eles permanece e efetivamente explica muitas das teses dominantes sobre a tradução naturalizadora ou encoberta como uma maneira adequada e justificada de incorporar o passado estrangeiro suprimindo a sua estranheza.

Considerando este cenário, uma breve análise de várias estratégias de tradução manifesta - para utilizar a terminologia de Juliane House ${ }^{2}-$ pode indicar que uma abordagem alternativa da historiografia estadunidense utiliza ao menos alguma inteligência onde, do ponto de vista acadêmico dominante, pode parecer não haver nenhuma. Como poetas tradutores, Robert Lowell e Ezra Pound ${ }^{3}$ não fizeram qualquer tentativa de afastamento do local sociológico da pesquisa acadêmica: Lowell agradeceu o apoio de uma impressionante lista de professores, linguistas experientes e poetas rigorosos - incluindo Renato Poggioli, Hannah Arendt, I.A. Richards, T.S. Eliot, Elizabeth Bishop e a Sra. Roman Jakobson -; no caso de Pound, a folha de rosto de Cathay reconhece sua famosa dívida aos Professores Fenollosa, Mori e Ariga, enquanto os Cantos 
incorporam uma quantidade de citações suficientes para preencher várias teses de doutorado. Pode-se dizer, assim, que os poetas em questão tiveram acesso razoável, se não privilegiado, a acervos de conhecimento bastante amplos, de modo que seria difícil tratar suas obras tradutórias como resultados de mera ignorância ou mesmo como curiosidades bizarras que ficaram por ser corrigidas. Seria mais apropriado dizer que ambos os poetas buscaram apoio e orientação, mas foram preparados para rejeitar abertamente os critérios de correção. As obras dos dois devem, assim, ser entendidas como resultado de tradução conscientemente manifesta, a ser observada em termos da utilização do erro para construir conhecimento a partir da distância dos documentos estrangeiros.

O erro é, por definição, triádico (o equivalente supostamente ideal, a tradução real e a diferença entre ambos), quando o simples equívoco tem estrutura binária (o equivalente supostamente ideal como correto e a tradução real como equivocada). Isso não quer dizer que Pound e Lowell não cometeram equívocos. Quando um poeta em tradução menciona "the River Kiang" (Pound, Cathay), a informação confiável de que "Kiang" significa "rio" produz uma simples oposição entre uma tradução correta e uma tradução incorreta; o único conhecimento importante produzido aqui, assim, é a infeliz suspeita de que Pound tinha uma compreensão bastante indireta do chinês. ${ }^{4}$

De modo parecido, quando Lowell traduz estes versos de Baudelaire:

Le temps! Il est, hélas! des coureurs sans répit, Comme le Juif errant et comme les apôtres... ("Le Voyage")

como

Time is a runner who can never stop... (Imitations)

a interpretação equivocada da sintaxe do francês ("il est" = "il y a") só faz produzir uma obstrução do bom senso: alguns versos adiante na tradução, o Tempo, sempre em corrida, de Lowell parece capaz de suspender-se ao ponto de pisotear aqueles que deveriam ser os que de fato correm:

And even when Time's heel is on our throat we can still hope, still cry, "on, on, let's go!"

Este lapso tem sua própria lógica linguística como equívoco e não diz nada de concreto a respeito de distância histórica. ${ }^{5}$

O equívoco torna-se erro apenas quando a diferença entre a equivalência e a tradução equivocada assume um especial sentido próprio. Assim, quando Lowell, em Imitations, traduz "lice" ("disputas" em francês) como "lice" (plural de "piolho" em inglês) na primeira tradução de Baudelaire (“To the Reader"), 
os falsos amigos poderiam sinalizar um mero equívoco, até encontrarmos, mais tarde, a última tradução, “The Lice Hunters", de Rimbaud. A tradução incorreta claramente funciona como um paralelismo narrativo intencional, separando em bloco esta seção Baudelaire-Rimbaud em Imitations e expressando uma voz autoral que não vem nem de Baudelaire, nem da união Baudelaire-Rimbaud, mas do narrador-historiador que ressalta esta união, que é Robert Lowell.

Esse uso controlado do erro é um princípio de composição subjacente tanto em Imitations como no posterior History. Para nosso argumento, no entanto, o mais breve e mais coerente Imitations basta para mostrar a estratégia tradutória básica em funcionamento aqui. O paralelismo narrativo de "lice", por exemplo, é continuado na repetição que une o primeiro e o último verso do livro como um todo, "mania of Achilles" concluindo em "mania to return" na última tradução, de Rilke. De fato, a palavra "mania" pode ser considerada uma recuperação ou redistribuição de um traço do sentido de "disputa" que se perdeu de "lice", assim utilizada para traduzir o "menin" de Homero ("ira divina", geralmente) e o "écroulements" (colapsos/quedas) de Rimbaud, e depois claramente acrescentada a Rilke para arrematar uma narrativa. Esses paralelismos e referências cruzadas entre textos traduzidos são tão frequentes que logo se torna impossível limitar a referencialidade ao âmbito de cada texto individual — os vários rios tornam-se um único rio; mulheres mitologicamente belas tornam-se uma única mulher; múltiplas referências a cães remetem a todos os cães; todas as viagens são a viagem; a morte é uma constante na obra inteira. Além disso, há uma dificuldade real de lembrar exatamente qual poeta está falando em qual texto: a apresentação é feita de tal forma que os nomes dos autores aparecem apenas em fonte pequena ao final de cada texto traduzido, em geral não na mesma página de seu início. A identificação do texto de partida torna-se uma parte inessencial no processo de leitura: se o leitor tem conhecimento prévio dos textos de partida, os ecos inevitavelmente suscitados são importantes exatamente como ecos e não como bases para correção. Definitivamente, esta não é uma simples antologia de poemas selecionados "porque não existe nada parecido com eles em inglês" ("Introdução"), mas um entrelaçamento temático cuidadosamente estruturado que, se lido na ordem de sua apresentação, se torna uma narrativa no sentido pleno do termo, organizando descobertas arqueológicas em termos de história como narrativa. ${ }^{6}$

Os vários fios narrativos entrelaçados efetivamente extraem terceiros fatores que transcendem das relações tradutórias de partida individuais. $\mathrm{O}$ resultado disso é uma série de personagens virtuais que se movem pela história como o espírito hegeliano, manifestando e potencialmente justificando uma estratégia de tradução que, confrontada com os detalhes da arqueologia filológica, poderia mesmo responder: "Tanto pior para os fatos".

A percepção deste discurso supra-tradutório desestabiliza as bases metodológicas de simples análises comparativas de traduções isoladas, especialmente quando elas aceitam, como no caso da leitura de "Le Bateau ivre"/“The Drunken Boat” feita por Amalia Rodríguez," o objetivo declarado 
de Lowell de "fazer o que os meus autores teriam feito se tivessem escrito seus poemas nos Estados Unidos de hoje" ("Introdução"). Embora a declaração possa ser lida como uma estratégia bastante clara de equivalência dinâmica, ela é radicalmente contrariada pela afirmação muito mais interessante, que aparece na mesma página, de que o tradutor "esperava algum sentido de conjunto.... É claro que nenhuma destas figuras ("meus autores") poderia, historicamente, ter tido acesso a este conjunto; também é óbvio que tal visão externa não poderia ser atribuída a elas nos Estados Unidos do fim da década de 1950, a não ser que se chamassem Robert Lowell. Não é de surpreender, então, que críticos avaliem, por exemplo, que a "beleza desconectada" das últimas estrofes de "The Drunken Boat" seja "profundamente estranha ao espírito e à voz de Rimbaud".

A discussão sobre este distanciamento será pouco produtiva enquanto as declarações contraditórias do tradutor forem consideradas critérios absolutos para a análise de traduções individuais. Na verdade, há motivos para ler a "Introdução" apenas como mais um fragmento de uma série de fragmentos textuais ${ }^{9}$ que formam Imitations, e também para ver as suas declarações contraditórias - em suma, uma problemática de enquadramento ${ }^{10}$ - como manifestações das tensões que alimentam a obra como um todo. Deste ponto de vista, a aparente adoção da equivalência dinâmica torna-se uma instância contextual de tradução manifesta (o pronome em primeira pessoa explicitamente descreve o que seria "descoagular", "desnudar", "remover do dialeto", "cortar ao meio", "acrescentar" etc.). Mais do que isso, é possível ver esta presença pronominal interferir num modo discursivo onde, em tese, ele não deveria ser encontrado: se a tradução pode ser definida como um modo de discurso no qual o enunciado "estou traduzindo" não pode ser performativo, o narrador de Imitations é bem-sucedido ao testar os próprios limites desta exclusão obrigatória.

Alguns exemplos são bastante evidentes. Quando Lowell faz Pasternak dizer:

The sequence of scenes was well thought out;

the last bow is in the cards

("Hamlet in Russia, A Soliloquy")

o fato de que o enunciado está no fim do penúltimo fragmento ao final do livro sugere que a voz que fala vem mais imediatamente do narrador de Imitations do que de qualquer outra fonte possível e potencialmente presente (Hamlet, Shakespeare ou Pasternak). Não é necessário ter acesso ao texto em russo para ler esta frase como uma tradução manifesta que desafia a própria possibilidade de um solilóquio no modo tradutório. Há muitos outros exemplos lúdicos, excêntricos ou simplesmente perspicazes. A tradução do verso de Baudelaire "Ah! ne jamais sortir des Nombres et des Êtres" como "Ah never to escape from numbers and form!" é intrigante como último verso do soneto de treze versos. De modo parecido, quando Rimbaud é conduzido a lembrar: 
Tom Thumb, the dreamer, I was knocking off my coupled rhymes...

("On the Road")

o acréscimo de "coupled" (Rimbaud menciona apenas "rimes") não apenas remete às formas de verso anteriores do poeta francês, mas também, e de modo mais evidente (aos olhos do leitor anglófono), à prática poética do próprio Lowell, notavelmente às rimas emparelhadas utilizadas em sua tradução de Phèdre. O acréscimo da sugestão de uma cópula psicoerótica unindo estes dois pronomes de primeira pessoa historicamente distanciados ("knocking off"/"coupled") não é em nada gratuito; ele ajuda a destacar o ambíguo "nós" implícito em cada primeira pessoa desde o início do discurso tradutório:

Sing for me, Muse, the mania of Achilles

(“The Killing of Lykaon”)

É estritamente impossível igualar este "me" a uma pessoa física em particular. Isso porque sabemos que Homero era um grupo e que a evocação formulaica abria um espaço semântico para cada contador individual da história, uma série potencialmente ilimitada de primeiras pessoas receptoras. Mas isso também se deve ao fato de que o tradutor, tendo se identificado e declarado suas intenções, inicia sua história de maneira a permitir que sua posição como sujeito transgrida a "Introdução" e adentre parte desta primeira pessoa do modo épico. Traduzir, neste sentido, implica apenas tornar-se o mais recente de uma longa linhagem de peregrinos contadores de histórias.

Esta primeira pessoa dividida é a chave para muitas das inquietações que críticos têm manifestado em suas interpretações de Imitations. É a chave para o que as vagas análises de "tom" têm identificado, intuitivamente, como um lirismo externalizado, como uma incompletude essencial da voz em primeira pessoa, ${ }^{11}$ e como uma "falta de um poema central" 12 que corresponda ao início e fim claramente demarcados da narrativa. Isto é, trata-se da chave para uma concepção recitativa de tradução que, despreocupada com a recente distinção entre criação individual e plágio, é capaz de tocar um "eu" que pode ter como contraponto não um leitor distante ou falecido, mas um "você" no presente. Isso efetivamente acontece no fragmento que, localizado de modo significativo no centro físico de Imitations, vai muito além da "Introdução" em resumir a importância discursiva da história em Lowell:

Stunningly simple Tourists, your pursuit is written in the tear-drops in your eyes! Spread out the packing cases of your loot, your azure sapphires made of seas and skies!

Oh trivial, childish minds!

How sour the knowledge travelers bring away! 
The world's monotonous and small; we see ourselves today, tomorrow, yesterday, an oasis of horror in sands of ennui! ("The Voyage")

Aqui é suficiente notar a mudança discursiva da terceira para a primeira pessoa: a voz que fala endereça um público de turistas, do qual ela se torna, doravante, uma parte crítica. Um objetor consciente em tempos de guerra, Lowell também se encontrava conscientemente incomodado com a anexação de capital cultural por parte de sua sociedade em tempos de paz.

Como no caso de Imitations, os Cantos de Ezra Pound iniciam com uma tradução de Homero e se desenvolvem a partir de princípios de composição que incorporam fragmentos traduzidos a uma obra inquestionavelmente pessoal. Mas as 149 páginas de Imitations são relativamente leves diante das 802 páginas dos Cantos. Enquanto que Lowell fez uso da seleção e do distanciamento para apresentar uma história como "narrativa", Pound estava obcecado pelo passado como uma coleção de pistas arqueológicas para uma verdade moral ${ }^{13}$ que não permitiria um todo narrativo. Lowell localizou a subjetividade no começo da Ilíada, obviamente um bom lugar para começar uma história de guerra; Pound embarcou, sem sujeito, a partir do Livro XI da Odisseia, perpetuamente in media res:

And so went down to the ship,

Set keel to breakers, forth on the godly sea, and We set up mast and sail...

Não haveria dúvida com relação à identidade deste "we" se o texto fosse lido como uma tradução direta de Homero. Entretanto, o trecho não é apresentado como tal: ele é apenas o primeiro de uma longa série de fragmentos, uma partida tanto para a subjetividade traduzida quanto para a subjetividade tradutora. $\mathrm{O}$ status tradutório do "we" ambiguamente compartilhado é identificado não por títulos, mas através de referências incorporadas como a já conhecida inserção no mesmo Canto I:

Lie quiet Divus. I mean, that is, Andreas Divus, In officina Wecheli, 1538, out of Homer, And he sailed...

Essa referência ao tradutor anterior, de quem Pound estava traduzindo, coloca não só uma segunda pessoa ("Lie quiet!") excluído do "we", mas também uma primeira pessoa ("I mean") que, como em Lowell, quase diz o indizível "estou traduzindo". Ao mesmo tempo, essa referência também assimila uma primeira pessoa do plural ("We set up mast and sail") que potencialmente inclui tanto o poeta 
quanto o leitor. ${ }^{14}$ Essa ambiguidade inclusiva é diferente daquela encontrada nos pronomes de Lowell: ela explicitamente incorpora uma experiência passada que, sendo apresentada pela passagem "And so" com o apagamento de, precisamente, um pronome ("And so went down"), é simplesmente o fragmento de uma série maior sem sujeito. Pound apaga e multiplica pronomes com frequência. Ambas as estratégias tornam habitualmente difícil identificar o sujeito exato de uma dada ação ou enunciação individual, muitas das quais são citações mal referenciadas. Se as personagens são importantes, seu modo preferencial de apresentação será o nome próprio (muitas vezes sem verbo) e, frequentemente, a data de enunciação. Assim, a expressão da subjetividade de incontáveis sujeitos é sistematicamente recusada. Uma citação pode ser identificada como vindo de "M. Curie", mas pode também ser de "some other scientist":

..."J'ai

Obtenu une brulure" M. Curie, or some other scientist

"Qui m’a coûté six mois de guérison."

(Canto XXIII) and continued his experiments.

A tradução aparece quatro cantos depois:

"J'ai obtenu" said M. Curie, or some other scientist

"A burn that cost me six months in curing,"

And continued his experiments.

(Canto XXVII)

Estes nomes próprios não são meros rótulos arbitrários de subjetividades históricas, mas funcionam como palavras em e para si mesmas: "Curie" é a razão de "in curing" ser uma tradução melhor de "de guérsion" do que a opção mais óbvia "to heal"; "Homer" é também "home"; "Divus" é claramente "diversion", ${ }^{15} \mathrm{e}$ assim por diante! O valor documental da palavra conta mais do que seu conteúdo subjetivo. Entretanto, isso vai muito além de uma série de trocadilhos ruins baseados em nomes próprios: o uso estritamente documental da língua é tão comum nos Cantos que se torna um princípio tradutório de composição. Em nenhum momento se explica ou analisa o contexto e o conteúdo da enunciação. Ao invés disso, a presença de superfície é mantida através da fragmentação e é interpretada através da tradução:

to keep him -

Per animarla - in mood to go on with the fighting. (Canto XXVI)

Ou ainda (mas há tantos exemplos, tantos nomes e termos estrangeiros, que esta seleção não deixa de ser arbitrária): 
"Leave no... omnem... as they say... volve lapidem...

"Stone unturned...

(Canto XXVI)

A produção dos Cantos é um constante e visível revirar de pedras, nem tanto para ver o que há debaixo delas, mas para utilizar o lado de baixo para localizar a próxima pedra a ser virada. Este processo segue à risca a noção de Jakobson de que "o sentido de qualquer signo linguístico é sua tradução em algum outro signo alternativo". ${ }^{16}$ Isto é, não se presume que o sentido esteja na pessoa, na intenção, no contexto ou em qualquer referente material ou transcendental do qual o signo possa simplesmente ser substituído. O sentido, diferentemente, é revelado no movimento de signo em signo, de superfície em superfície, em um processo que nunca para de buscar alguma verdade escondida em ou entre signos (em que a maior parte da verdade é a acumulação de valor excedente). Sem dúvida é por isso que o valor documental do material textual é constantemente ressaltado por cortes e deslocamentos, por formas exclusivamente escritas (“wd/", "cd/", “@”), por modificações de formas escritas de modo a traduzir a forma falada (colégio em inglês é "kawledg"; religião em espanhol é "reliHion"), e pelo constante retorno de frases em diferentes contextos, em modo original ou traduzido, com quase nenhuma consideração por qualquer aparência de ordenação cronológica. Vale destacar que isso é feito com todas as línguas e dentro de línguas individuais. É difícil acusar Pound de não ter compreendido o valor pictórico dos ideogramas chineses quando está claro que ele aplicou a mesma interpretação lúdica dos níveis de superfície aos nomes próprios europeus e a enunciações em geral.

Embora possa ser fácil situar Pound dentro da moda da desconstrução, devese enfatizar que, como no caso de Laforgue, seu trabalho no nível de superfície de enunciados permanece um processo de produção de conhecimento crítico. Um exemplo breve pode ilustrar a importância deste processo de tradução:

\section{OY TIS}

"I am noman, my name is noman" but Wanjina is, shall we say, Ouan Jin or the man with an education and whose mouth was removed by his father because he made too many things whereby cluttering the bushman's baggage vide the expedition of Frobenius' pupils about 1938 to Auss'ralia

Ouan Jin spoke and thereby created the names

the bane of men moving thereby making clutter and so his mouth was removed as you will find it removed in his pictures (Canto LXXIV, primeiro dos "Pisian Cantos").

A conflação de contextos é motivada por semelhanças superficiais entre "Wen Jen" (uma figura chinesa de sabedoria silenciosa) e "Wanjina" (figuras aborígenes pintadas em cavernas do noroeste da Austrália; termo normalmente transcrito 
como "Wondjina"). ${ }^{17}$ A conflação em nível de significantes ("shall we say") serve para unir diversos princípios relacionados: a negação do nome próprio por Odisseu, o homem instruído de quem a boca foi removida e a figura aborígene pintada sem a boca. No contexto dos "Pisian Cantos", escritos em uma prisão militar estadunidense, o tema da fala suprimida é utilizado como um protesto contra a venda de armas, a promoção econômica da guerra, um mercado onde "there is no clutter, no saturation" ["não há desordem, nem saturação"]. Porém, a elaboração desta afirmação complexa também traduz de maneira poderosa um elemento que, de acordo com outros procedimentos, permaneceria intraduzível.

Os etnólogos não têm sido capazes de dizer porque o Wondjina não tem boca; eles têm sido incapazes de traduzir essa ausência significativa em alguma hipótese de conhecimento existente. Quando A. P. Elkin perguntou aos nativos sobre isso, "eles simplesmente responderam que não era possível desenhar uma boca; ao que parece, a eficácia da pintura [de provocar chuva] depende desta ausência". ${ }^{18}$ Abordagens comparativas foram frustradas de modo similar por respostas que não são nem de acordo nem de desacordo. Lévy-Bruhl, por exemplo, comparou os Wondjina aos adereços de cabeça dos gåri encontrados na Nova Guiné e ilustrados sem boca, como relatado por Wirz. Mas o que então significa gåri? Wirz só poderia fazer conjecturas, já que "os Marind-Anim responderam 'sim' a todas as perguntas." ${ }^{19}$

O interesse deste exemplo está no fato de que o processo tradutório como elaborado por Quine não consegue nem mesmo ser iniciado em situações em que a resposta do sujeito não é nem positiva nem negativa ${ }^{20}$. Pound, entretanto, não precisava de nenhum consentimento de nativos para compreender que a boca havia sido removida para que o conhecimento fosse restringido. Certa verdade poderia ser construída a partir dos próprios significantes.

A historiografia de Pound é a da letra como revelação, e não de algum espírito dinâmico que poderia prover relações narrativas entre elementos dispersos. Como princípios morais existem independentemente de tempo e espaço, manifestações isoladas da mesma verdade podem entrar em uma interpretação mútua. A despeito de tudo o que tem sido dito sobre as estratégias tradutórias de Pound, ${ }^{21}$ as manifestações se traduzem; elas não requerem a organização em torno de uma subjetividade ou nação central; o tradutor é então sempre já um "nós" ativamente engajado na arqueologia de textos, em protesto participativo contra absorções culturais falsamente passivas.

Imitations e The Cantos são ambos poemas de guerra; ambos são marcados por um pessimismo histórico; ambos traduzem a cultura europeia de modo a expressar esse pessimismo. Entretanto, a história de Lowell abrange forças empenhadas em se desenvolverem no tempo e espaço do seu tradutor estadunidense e como parte crítica da sociedade estadunidense, quando a arqueologia de Pound rejeita o 
ponto de vista de um leitor ou crítico, em última instância, acadêmico, tornandose a obra de um tradutor que, em nome do que era percebido como verdade moral, era também um traidor.

Notes

1. Publicado originalmente sob o título "Resistant Translation Strategies in Robert Lowell's Imitations and Ezra Pound's Cantos" no livro Cross-Words. Issues and Debates in Literary and Non-literary Translating, editado por Christine \& Ian Mason, Liège: L3, 1995, 159-171. Nossos agradecimentos ao Professor Anthony Pym, que autorizou esta tradução. Traduzido por Juliana Steil (UFPel) e Otávio Guimarães Tavares (UFPA).

2. Juliane House, A Model for Translation Quality Assessment, TBL Verlag Gunter Narr, Tübingen, 1977.

3. Robert Lowell, Imitations, Farrar, Straus and Giroux, New York, 1958; Ezra Pound, The Cantos: Revised Collection Edition (Cantos 1 - 117), Faber and Faber, London, 1975.

4. Kenner, com razão, dispensa tais equívocos como "desvios realizados de olhos abertos" e, mais que isso, salienta que "não se trata de uma sedução por ideogramas compreendidos parcialmente; não há ideogramas em evidência nestas páginas de Fenollosa" (p. 213). Outros equívocos de Pound são apontados por Christine Brooke-Rose, A ZBC of Ezra Pound, Faber and Faber, London, 1971, pp. $84 \mathrm{ff}$.

5. Listas de equívocos cometidos por Lowell podem ser encontradas em Critics on Robert Lowell, ed. J. Price, George Allen \& Unwin, London, 1972, especialmente em "Meaning and Tone", de C. Chadwick.

6. Para citar apenas uma das várias leituras narrativas possíveis, o mito básico extraído da Ilíada - "God's will was working out, / from that time when first fell apart fighting / Atrides, king of men, and that god, Achilles..." - torna-se uma problemática desenvolvida através de muitas referências como (por ordem de apresentação): "I set that man above the gods and heroes" (Sappho), "These mighty men ... / who will correct the great?..." (Der Wilde Alexander), "I see that none escape /... These poor corpses were once / kings... Helen has paid this debt" (Villon), "in the end they are much of a pair / my twin gladiator beauties... Soon I must lose all these half-gods / that made my world so agonizingly half-joyful" (Heine), "God of armies, is this the end?' he cried.... 'No, Napoleon"' (Hugo: L'Expiation), "I see the galleys bleed with dawn, / and shark with muffled rowlocks into Troy" (Valéry, Hélène), "there is nothing / sorrier than the marriage of two deaths" (Annensky), "le roi soleil, / hears the gods' Homeric laughter from the dignitaries' box" (Pasternak), "The overpaid gladiator must die in earnest" (Pasternak), "body and gravity, miraculously multiplied by its mania to return" (Rilke)...

7. Amalia Rodríguez Monroy, “An English 'Imitation’ of Rimbaud: An Exercise in Comparative Translation", Quaderns de Traducció i Interpretació, EUTI, Universitat Autònoma de Barcelona, 3, 1983, pp. 7-22.

8. Ibid., p. 22.

9. Em certos aspectos, esta "Introdução" é ela mesma tradutória: embora os comentários críticos normalmente façam referência obrigatória à noção de "imitação" de Dryden, a fonte pertinente aqui é o texto que ocasionou o comentário de Dryden, a saber, o de Cowley (1656): "Aproveitei, rejeitei e acrescentei o que quis nestas duas odes de Píndaro; também não persegui o objetivo de mostrar ao leitor exatamente o que ele falava, mas qual era a sua maneira de falar" (citado por E.A. Nida, Toward a Science of Translating, E.A. Brill, Leiden, 1964, p. 17).

10. Não é sequer possível dizer que a "Introdução" é o primeiro dos fragmentos textuais da obra, uma vez que o "Índice" (que lista 63 textos traduzidos mas exclui a tradução de 
"Die Tauben", de Rilke) não corresponde nem ao corpo da obra (onde o texto de Rilke de fato é apresentado como tradução), nem à segunda orelha, que anuncia "sessenta e seis poemas". Uma explicação possível é que o "Índice" e a "Introdução" devam ser considerados poemas $(63+1+2=66)$. Uma explicação menos desconcertante seria que os dois limiares textuais falsamente suprimiram o trabalho em progresso (que seria, de fato, continuado em History) e uma subjetividade de escrita que constantemente evocava fronteiras instáveis entre material e processo.

11. Cf. Geoffrey Hill, "Contrasts and Repetition”, em Critics on Robert Lowell, op. cit.

12. Cf. Stephen Yenser, Circle to Circle. The Poetry of Robert Lowell, University of California Press, Los Angeles, London, 1975: “Em princípio, parece que Lowell talvez tenha deixado que seu arranjo cronológico geral subvertesse seu padrão narrativo..." (p. 184). Tendo falhado em perceber o papel central do "você" endereçado a Turistas, Yenser conclui que Imitations, como um todo, é "uma alegoria da luta do poeta por encontrar sua própria tarefa” (p. 191).

13. A ambição dos Cantos foi descrita como a de "traçar os modos como a desigualdade econômica tem sido um câncer no corpo da civilização"; cf. William M. Chace, The Political Identities of Ezra Pound and T.S. Eliot, Stanford University Press, Stanford, 1973, p. 10.

14. A ambiguidade inclusiva com relação à primeira pessoa é, de fato, somente quebrada no final apócrifo dos Cantos publicados, em que o "I" é distanciado da estética do texto, como em "i.e. it coheres all right / even if my notes do not cohere" [i.e. é coerente sim / mesmo que as minhas notas não sejam coerentes] (CXVI); ou novamente: "I, one thing, as a relation to one thing; / Hui sees relation to tem" [Eu, uma coisa relacionado a uma coisa; / Hui vê relação com dez] (notas para CXI). É inteiramente possível ler "Hui" como "we”.

15. “... nem ligo eu muito por qual nome Andreas era conhecido na sua vida particular", Ezra Pound, “Translators of Greek: Early Translators of Homer”, in Literary Essays of Ezra Pound, Faber and Faber, London, 1954, p. 259.

16. Roman Jakobson, “On Linguistic Aspects of Translation”, em Ruben Brower (ed.) On Translation, Oxford University Press, New York, 1966.

17. Cf. Brooke-Rose, op cit., p. 4.

18. A. P. Elkin, “Rock-paintings of N.W. Australia, Oceania, 1 (1930).

19. P. Wirz, Die Marind-anim von holländisch Süd-Neu-Guinea, II, p. 124; citado por Lucien Lévy-Bruhl, La Mythologie primitive, Presses Universitaires de France, Paris, 1935, p. 138.

20. W.V.O. Quine, “Translation and Meaning”, em Word and Object, MIT Press, Cambridge Mass., 1960.

21. Kenner vê a "homenagem mimética" de Pound como uma reação contra estratégias do século dezenove baseadas na inspiração poética (op. cit.); para Borges, Pound estava voltando às estratégias literalistas usadas nos séculos treze e quatorze (em "Note sur Ezra Pound, traducteur", em L'Herne: Ezra Pound, 2, Paris, 1965, p. 233); Jean-Pierre Attal tenta generalizar tal "homenagem tradutória" como o retorno a um modo latino de composição ("Commentaire sur Homage to Sextus Propertius", ibid., p. 547); já Nida confunde o dizer "Make it new" como preceito para a equivalência dinâmica (op. cit.).

\section{Referências}

BROOKE-ROSE, C. A ZBC of Ezra Pound. London: Faber and Faber, 1971.

CHACE, W. M. The Political Identities of Ezra Pound and T.S. Eliot. Stanford: Stanford University Press, 1973. 
HOUSE, J. A Model for Translation Quality Assessment. Tübingen: TBL Verlag Gunter Narr, 1977.

JAKOBSON, R. On Linguistic Aspects of Translation. In: BROWER, R. (Ed.) On Translation. New York: Oxford University Press, 1966.

LÉVY-BRUHL, L. La Mythologie primitive. Paris: Presses Universitaires de France, 1935.

LOWELL, R. Imitations. New York: Farrar, Straus and Giroux, 1958.

MONROY, A. R. An English 'Imitation' of Rimbaud: An Exercise in Comparative Translation. Quaderns de Traducció I Interpretació, Barcelona, n. 3, pp. 7-22, 1983. EUTI, Universitat Autònoma de Barcelona.

NIDA, E. A. Toward a Science of Translating. Leiden: E.A. Brill, 1964.

POUND, E. The Cantos: Revised Collection Edition (Cantos 1 - 117). London: Faber and Faber, 1975.

POUND, E. Translators of Greek: Early Translators of Homer. In: . Literary Essays of Ezra Pound. Edited with an Introduction by T.S. Eliot. London: Faber and Faber, 1954.

QUINE, W. v. O. Translation and Meaning. In: Word and Object. Cambridge Mass.: MIT Press, 1960.

YENSER, S. Circle to Circle. The Poetry of Robert Lowell. Los Angeles / London: University of California Press, 1975. 